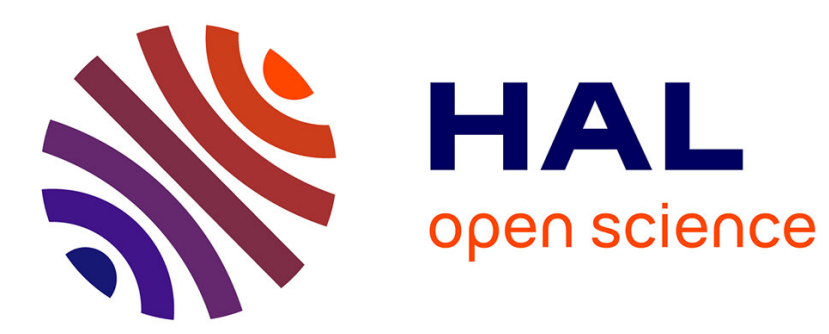

\title{
Planum Temporale grey matter volume asymmetries in new-born monkeys (Papio anubis)
}

Yannick Becker, Romane Phelipon, Julien Sein, Lionel Velly, Luc Renaud, Adrien Meguerditchian

\section{- To cite this version:}

Yannick Becker, Romane Phelipon, Julien Sein, Lionel Velly, Luc Renaud, et al.. Planum Temporale grey matter volume asymmetries in new-born monkeys (Papio anubis). Brain Structure and Function, 2021, 10.1007/s00429-021-02278-9 . hal-03196979

\section{HAL Id: hal-03196979 \\ https://hal-amu.archives-ouvertes.fr/hal-03196979}

Submitted on 13 Apr 2021

HAL is a multi-disciplinary open access archive for the deposit and dissemination of scientific research documents, whether they are published or not. The documents may come from teaching and research institutions in France or abroad, or from public or private research centers.
L'archive ouverte pluridisciplinaire HAL, est destinée au dépôt et à la diffusion de documents scientifiques de niveau recherche, publiés ou non, émanant des établissements d'enseignement et de recherche français ou étrangers, des laboratoires publics ou privés. 


\section{Planum Temporale grey matter volume asymmetries in new-born monkeys (Papio anubis)}

Yannick Becker ${ }^{1,2}$, Romane Phelipon ${ }^{1}$, Julien Sein $^{2}$, Lionel Velly ${ }^{2}$, Luc Renaud ${ }^{2}$ and Adrien Meguerditchian $^{* 1,3}$

*Corresponding Author: adrien.meguerditchian@univ-amu.fr

${ }^{1}$ Laboratoire de Psychologie Cognitive, UMR 7290, Université Aix-Marseille / CNRS, 13331

Marseille, France

${ }^{2}$ Institut des Neurosciences de la Timone, UMR 7289, Université Aix-Marseille / CNRS, 13005

Marseille, France

${ }^{3}$ Station de Primatologie, CNRS, UPS846, 13790 Rousset, France

\section{Abstract}

The Planum Temporale $(P T)$ is one of the key hubs of the language network in the human brain. The gross asymmetry of this perisylvian region toward the left brain was considered as the most emblematic marker of hemispheric specialization of language processes in the brain. Interestingly, this neuroanatomical signature was documented also in newborn infants and preterms, suggesting the early brain's readiness for language acquisition. Nevertheless, this latter interpretation was questioned by a recent report in nonhuman primates of a potential similar signature in newborn baboons Papio anubis based on $P T$ surface measures. Whether this "tip of the iceberg" $P T$ asymmetry is actually reflecting asymmetry of its underlying grey matter volume remain unclear but critical to investigate potential continuities of cortical specialization with human infants. Here we report a population-level leftward asymmetry of the Planum Temporale grey matter volume in in vivo 34 newborn baboons Papio anubis, which showed intra-individual positive correlation with $P T$ surface's asymmetry measures but also a more pronounced degree of leftward asymmetry at the population-level. This finding demonstrates that $P T$ leftward structural asymmetry in this Old World monkey species is a robust phenomenon in early primate development, which clearly speaks for a continuity with early human brain specialization. Results also strengthen the hypothesis that early PT asymmetry might be not a human-specific marker for the pre-wired language-ready brain in infants.

\section{Introduction}

The majority of language processes is asymmetric in the human brain, involving a specialization of the left hemisphere (Vigneau et al., 2006). The most emblematic marker of such a language cerebral organization is the gross asymmetry of the Planum Temporale $(P T)$ toward the left hemisphere. This perisylvian region, which constitutes the floor of the Sylvian fissure, posterior to Heschl's gyrus and overlaps with Wernicke's area, is one of the key hubs of the language network in 
37 the human brain. In fact, the left $P T$ was significantly activated in a variety of language processing

38 tasks in adults (Shapleske et al., 1999, Vigneau et al., 2006, Josse et al., 2006).

39 Since the first discovery that the $P T$ was larger in the left hemisphere than the right in most 40 adults (Geschwind and Levitsky, 1968), it remains unclear, whether this feature constitutes a good 41 marker of language functional lateralization. While some studies reported no match between structural 42 and functional asymmetry of this region (Keller, 2011; Greve, 2013), clinical studies found that 43 atypical $P T$ structural asymmetry were associated with multiple language deficits (Borovsky et al., 44 2007; Dronkers et al., 2004; Foundas et al., 2004; Wernicke, 1874). In addition, in a recent 45 study, higher density of dendrites and axons in the $P T$ were associated with faster neurophysiological 46 processing of auditory speech (Ocklenburg et al., 2018). Moreover, in a second recent study, 47 structural $P T$ asymmetry was found associated with functional lateralization of an adjacent auditory 48 area at the end of the Sylvian fissure during a language task (Tzourio-Mazoyer et al., 2018).

Interestingly, leftward PT asymmetry was detected early in the development at both the functional level in three-month-old infants in response to speech (Dehane-Lambertz et al., 2002) and at the structural level in newborn and in preterms (Witelson and Pallie, 1973; Wada, 1975; Chi et al., 1977, Dubois et al., 2010; Hill et al., 2010; Glasel et al., 2011). Such early features of language brain lateralization suggest that the infant brain might be already pre-wired for language acquisition (e.g. Dehaene-Lambertz et al., 2002).

However, the human uniqueness of structural $P T$ asymmetry was questioned by studies highlighting also a population-level leftward asymmetry by $P T$ surface measures in chimpanzees (Gannon et al. 1998, Hopkins et al., 1998, Spocter et al. 2020) and in baboons (Marie et al. 2018). In this latter old world monkey species, $P T$ leftward surface biases were found not only in adults but also recently in newborn baboons (Becker et al., 2021, see also Xia et al., 2019 for a study in macaques using cortical surface-based morphometry), suggesting it might reflect the asymmetry of its underlying grey matter volume and is thus not specific to human early brain development. In fact, $P T$ surface area measures quantified the depth of the sylvian fissure's floor. It might be thus not excluded that the asymmetry of the sulcal surface area of this region might be an appropriate indicator of the asymmetry of the juxtaposing grey matter volume of the $P T$. This hypothesis is supported by few studies in adult chimpanzees which focused on $P T$ grey matter volume asymmetry according to both ROI manual tracing (Hopkins and Nir, 2010; Lyn et al., 2011) and voxel-based morphometry (Hopkins et al., 
69 In the present study, we further explore this hypothesis in 34 newborn baboons by quantifying the grey

70 matter volume of the left and right $P T$ from in vivo MRI brain scans (Becker et al., 2021). The aim of 71 the follow-up study is thus to investigate early individual and population-level asymmetries of the $P T$ 72 grey matter volume in newborn nonhuman primates and their potential consistencies with $P T$ surface 73 asymmetries measures within the same cohort of subjects used in Becker et al.'s study (2021).

\section{4}

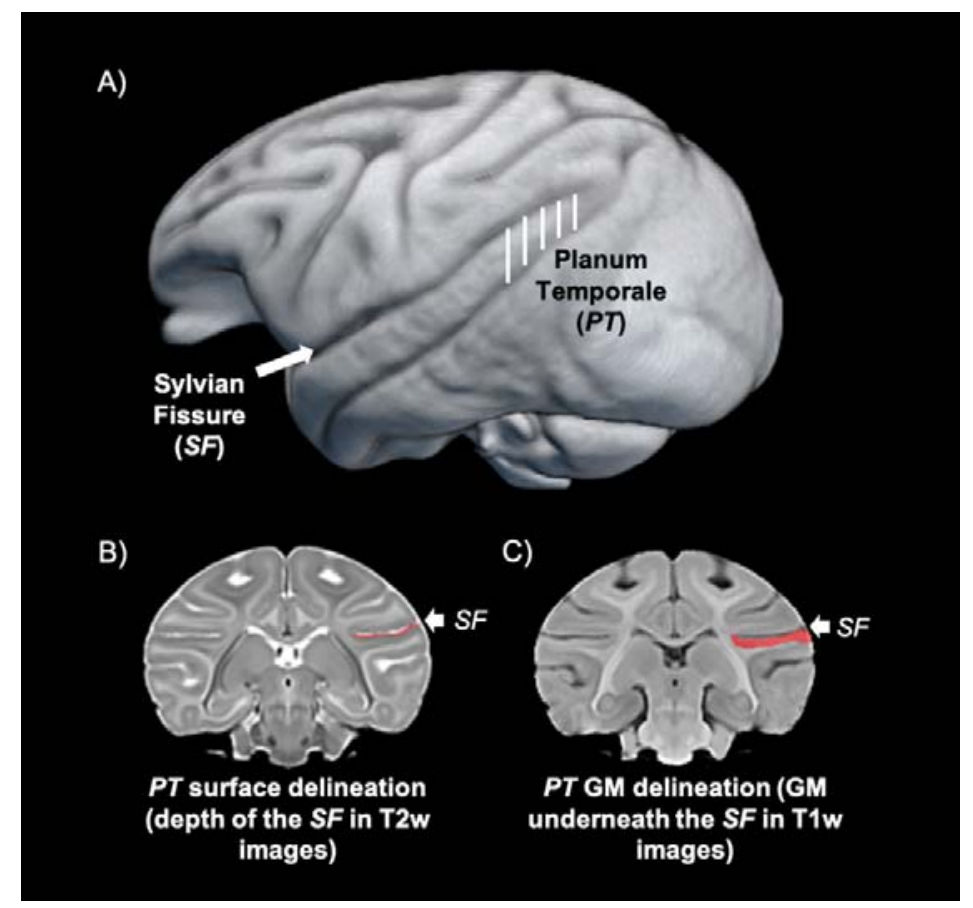

Figure 1. (A) 3D reconstruction of a newborn baboon brain with the $P T$ region highlighted by the white lines (B) Coronal slice of the same subject with the delineation of the Sylvian Fissure's floor (in red), used for $P T$ surface measures (C)) Coronal slice of the same subject with the delineation of the grey matter (in red) underneath the Sylvian Fissure, used for $P T$ volume measures.

\section{Materials and Methods}

\section{Subjects}

Subjects ranged from 4 to 165 days of age (Mean: 32.63; SD: 6.13) and included 21 males and 14 females. (see table in supplementary methods with subjects' details)

4 All monkeys are housed in social groups at the Station de Primatologie CNRS (UPS 846, Rousset, 85 France) and have free access to outdoor areas connected to indoor areas. All subjects are born in 6 captivity from 1 (F1) or 2 generations (F2). Wooden and metallic structures enrich the enclosures. 7 Feeding times are held four times a day with seeds, monkey pellets and fresh fruits and vegetables. 8 Water is available ad libitum. 
91

92

93

94

95

96

97

98

99

100

101

102

103

104

105

106

107

108

109

110

111

112

113

114

115

116

117

118

119

120

121

122

123

124

125

126

\section{MRI Image acquisition}

Structural magnetic resonance images (MRI) were collected from a sample of 35 baboons (September 2017 to March 2020). Animals were minimally anesthetized by a veterinarian; and vital functions were monitored during the scans. High-resolution structural T1-weighted brain images were obtained with MPRAGE sequences $(0.4 \mathrm{~mm}$ isotropic, $\mathrm{TR}=2500 \mathrm{~ms}, \mathrm{TE}=3.01 \mathrm{~ms})$ with the subject in the supine position on a Siemens 3T Magnetom Prisma scanner and using two $11 \mathrm{~cm}$ receive-only loop coils (for more detailed procedure: Becker et al., 2021). At the end of the MRI session, when fully awaked from anaesthesia, baboons were carefully put back with their mother and then transported for immediate (or delayed) reintroduction into their social groups under staff monitoring.

\section{Preprocessing of Anatomical MRI}

Anatomical $\mathrm{T} 1 \mathrm{w}$ images were noise corrected with the spatially adaptive nonlocal means denoising filter (Manjón et al., 2010) implemented in Cat12 toolbox (http://www.neuro.uni-jena.de/cat/) included in SPM12 (http://www.fil.ion.ucl.ac.uk/), which runs on MATLAB (R2014a). Next, each image was manually oriented using ITK-Snap 3.6 according anterior and posterior commissures plane and the interhemispheric fissure plane.

\section{Manual Delineation of the Planum Temporale's grey matter volume}

Manual delineation was conducted with "ANALYZE 11.0 (AnalyzeDirect)" software and following the delimitation instructions established in previous $P T$ studies in nonhuman primates using MRI (e.g., Hopkins and Nir, 2010; Lyn et al., 2011; Meguerditchian et al., 2012; Marie et al., 2018; Becker et al., 2021). The delineation of the posterior edge of the $P T$ is defined by the most caudal section showing the Sylvian fissure. In humans, the anterior edge of the $P T$ is delimited by the Heschl gyrus, however, in baboons the Heschl gyrus is not clearly detectable, therefore to delineate the anterior edge of the $P T$ here, the most anterior cut including the Sylvius Fissure was used when the insula closes completely (when the insula fissure disappears completely posteriorly). For each slice, manual tracing was conducted from the medial most point of the Sylvius Fissure, to the most lateral point, following the most ventral edge of the fissure. Next, the raters followed the grey matter to its most inferior edge of the grey/white matter boundary. When ambiguous, the imaginary prolongation of the Sylvian Fissure was used to differentiate between the grey matter of interest and the more dorsal gyrus. This step is repeated on the next cut, advancing posteriorly, until the Sylvius Fissure disappears. If the fissure forked in an ascending or descending direction, it was preferable to follow the descending one. This manual tracing was done on the coronal plane and not sagittal, as it gives the best assessment of the total depth of the Sylvius pit, which is the "ground" of the PT. The manual delimitation was carried out via a graphic tablet (WACOM cintiq 13HD). Out of the 256 slices included in the MRI images, the $P T$ appeared in about 20 slices (Supplementary Figure 1) 
127 For each subject, an Asymmetry Quotient (AQ) of the left (L) and the right (R) grey matter volume

128 was computed $\mathrm{AQ}=(\mathrm{R}-\mathrm{L}) /[(\mathrm{R}+\mathrm{L}) \times 0.5]$ with the sign indicating the direction of asymmetry

129 (negative: left side, positive: right side) and the value, the strength of asymmetry. Further, as reported

130 by Hopkins and Nir (2010) for humans and great apes, the AQ was also used to classify the subjects as

131 left-hemispheric biased ( $\mathrm{AQ} \leq-0.025)$, right biased ( $\mathrm{AQ} \geq 0.025)$, or non-significantly biased "ambi"

$132(-0.025<\mathrm{AQ}<0.025)$.

133 To reduce potential observer-dependent manual tracing biases, all the PTs grey matter volume were

134 traced by a rater different from the one who traced the $P T$ surface in Becker et al. (2021). The rater of

135 the present study was blind to the $P T$ surface's tracing, data and results of Becker et al. (2021).

136 Statistics were conducted with R 3.6.1 (R Core Team (2017). R: A language and environment for

137 statistical computing. R Foundation for Statistical Computing, Vienna, Austria. URL https://www.R-

138 project.org/.)

139

140

\section{Results}

141 PT Grey matter volume measures

142 We found a significant leftward asymmetry of the $P T$ grey matter volume at a group-level in 34 143 newborn baboons according to a one sample t-test in the 34 subjects AQ scores (see Figure 2), Mean $144 \mathrm{AQ}=-0.121, \quad 0.169 \mathrm{SD} ; t(33)=-4.2, p<0.0001$. Categorization of individual AQ showed also a 145 majority of leftward $P T$-biased individuals: 24 baboons exhibited a leftward hemispheric $P T$ bias 146 (70.6\%) whereas 7 exhibited a rightward $P T$ bias (19.6\%) and 3 no PT bias (8.8\%). The number of 147 leftward $P T$-biased individuals was significantly greater than the number of rightward $P T$-biased 148 according to chi-square test $(\chi 2=21.94, p<0.0001)$.

149 Multiple linear regression analyses showed that the right $P T$ volume $(p<0.001)$ and the left $P T$ 150 volume $(p<0.001)$ predict $P T$ asymmetry strength, but not the subject's sex, age nor brain volume. 151

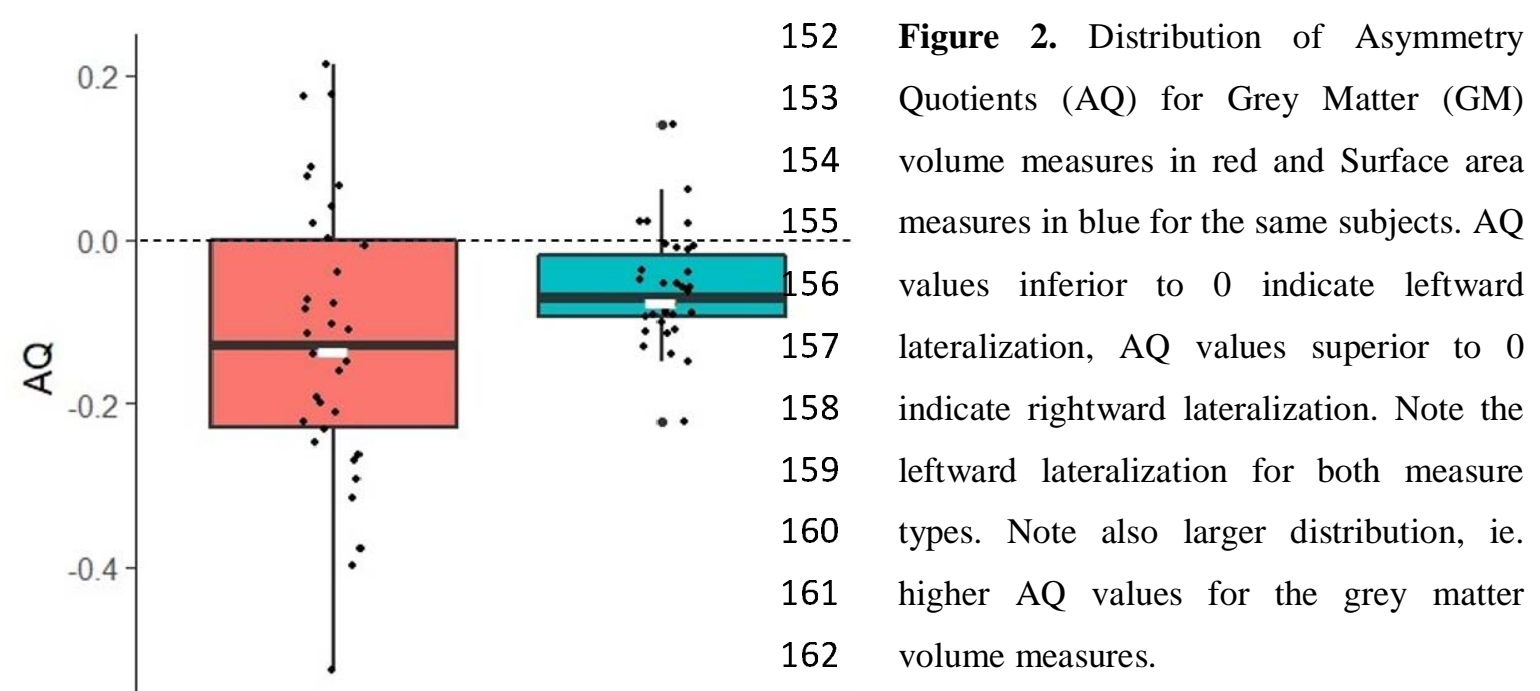


165 Within the 34 individuals for whom data of $P T$ surface and $P T$ grey matter volume measures were independently traced by two different raters blind to the results of each other, a significant positive intra-individual correlation of AQ scores was found between $P T$ surface and $P T$ grey matter volume. $r(34)=0.36, p<0.037$.

169 In comparison to previous surface $P T$ measures (Becker et al., 2021), 22 were consistent in hemispheric lateralization classification (i.e., 20 leftward, 1 rightward and 1 ambi) and 4 subjects switched direction of hemispheric $P T$ bias (i.e., from leftward bias for $P T$ surface to rightward bias for $P T$ grey matter volume). Among the remaining 8 subjects, 6 which previously showed no significant bias (i.e. "ambi") for the $P T$ surface were found significantly lateralized for the $P T$ grey matter volume and 2 which were previously classified as significantly lateralized for the $P T$ surface were classified as "ambi" for the $P T$ grey matter volume.

176

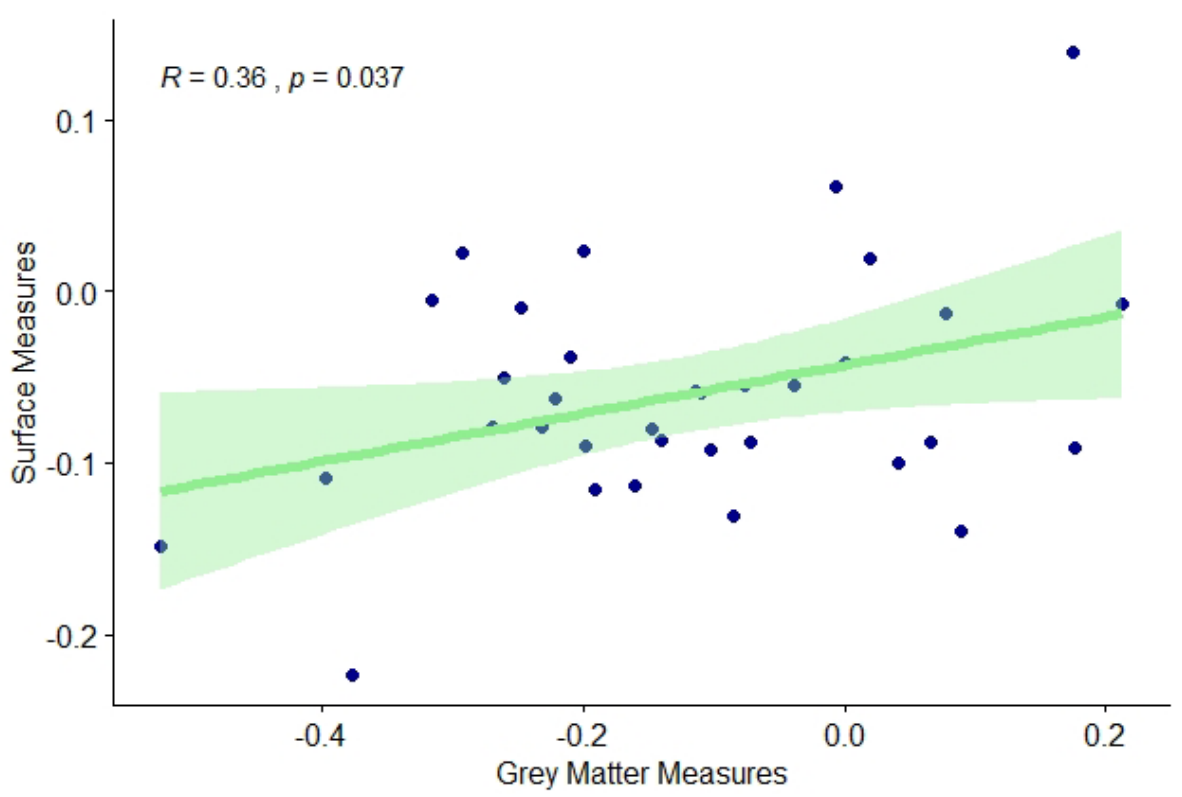

Figure 3. Pearson correlation between PT Surface and Grey matter volume measures.

178

179

180

181

182

183

184

185

186

\section{Discussion:}

We find for the first time both individual and leftward population-level grey matter volume asymmetries of the Planum Temporale not only in Old World monkeys but also in a newborn nonhuman primate. These results showed intra-individual positive correlation with previous published $P T$ surface measures on the same subjects as well as consistent leftward PT asymmetry (Becker et al., 2021) and suggesting $P T$ surface measures may therefore reflect its underlying grey matter volume. The distributions of individual $P T$ hemispheric preferences (left, right or ambi) are quite 
187 similar between volumetric grey matter and surfacic measures, especially for the left lateralized

188 subjects, although some inconsistency was noticed at the individual level in a minority of subjects. It 189 remains unclear whether those variations are due to interrater-dependent variability in the measures, 190 which leads few subjects to switch categories or to the possibility that $P T$ surface measures are not 191 entirely perfect "tip of the iceberg" predictors of the $P T$ grey matter volume, especially for the subjects 192 initially classified as ambiguously biased for $P T$ surface. In fact, almost all of those latter "ambi" 193 newborns (6 out of 7) were found to be significantly lateralized for $P T$ grey volume. In addition, AQ 194 values were overall higher in grey matter measures (AQ -0.121 12.1\%) compared to surface measures 195 (AQ -0.073 7.3\%). A similar effect was found in Hopkins and Nir's paper (2010), which showed a $1964.96 \%$ larger left hemisphere when measuring its surface and $6.63 \%$ larger hemisphere when 197 measuring its grey matter. Therefore, measures of grey matter volume may be more likely to capture 198 interindividual differences of the $P T$ asymmetry, whereas the surface measures may only scratch the 199 top of the $P T$ iceberg.

200 Interestingly, in a previous study in chimpanzees, Hopkins and Nir (2010) noted that leftward $201 \quad P T$ grey matter volume asymmetry constituted a better marker for the chimpanzee's right-hand 202 preference in communicative pointing gestures than PT surface (but see Meguerditchian et al., 2012). 203 This latter study suggested the hypothesis that asymmetry of $P T$ grey matter volume might be 204 associated to functional asymmetry related to properties of gestural communication in apes, which 205 have been found to share common features with human language such as intentionality, flexibility or 206 referential properties (i.e., Liebal et al., 2013). Communicative manual gestures in baboons were also 207 described in the literature (e.g., Molesti et al., 2020) as well as their chimpanzees-like manual 208 lateralization patterns (Meguerditchian et al. 2013). Follow-up behavioral observations on gestural 209 lateralization for communication in our sample of growing baboons will advance this question, once 210 the focal subjects develop their full gestural repertoire. Specifically, taking advantage of the stronger $211 P T$ asymmetries described in the present study for grey matter volume in comparison to surface 212 measures, we could further investigate whether those early brain asymmetries might predict the 213 gestural lateralization's emergence in later development.

214 In conclusion, the present finding in nonhuman infants provides additional support to the hypothesis of 215 a continuity between nonhuman and human primates concerning early leftward structural $P T$

216 asymmetry in brain development. Early $P T$ asymmetry might be thus not a human-specific marker for

217 the pre-wired language-ready brain in infants. Nevertheless, it might be not excluded that this common

218 anatomical signature is related to an ancient shared cognitive process at the heart of language

219 evolution.

220

\section{Acknowledgments}

222 We are very grateful to the vets Romain Lacoste and Marie Dumasy as well as the anesthetist Laura 223 Laura Giacomino for supervising the first health and anesthesia monitoring, Emilie Rapha for great 
assistance and animal care, Frederic Charlin, as well as the care staff of the Station de Primatologie, such as Valérie Moulin, Brigitte Rimbaud, Richard Francioly, the vets Pascaline Boitelle, Alexia Cermolacce \& Janneke Verschoor, the behavioral manager Pau Molina, the engineers of the MRI center, Bruno Nazarian and Jean-Luc Anton for coordinating the MRI sessions.

\section{Funding}

230 The project has received funding from the European Research Council under the European Union's 231 Horizon 2020 research and innovation program grant agreement No 716931 - GESTIMAGE - ERC232 2016-STG (P.I. Adrien Meguerditchian), from the French “Agence Nationale de le Recherche” ANR233 16-CONV-0002 (ILCB) and the Excellence Initiative of Aix-Marseille University (A*MIDEX). This 234 MRI acquisitions were done at the Center IRM-INT (UMR 7289, AMU-CNRS), platform member of France Life Imaging network (grant ANR-11-INBS-0006).

\section{Conflicts of interest/Competing interests}

Not applicable

239

\section{Availability of data and material}

241 See supplementary material

242

\section{Code availability}

244 Not applicable

\section{Authors' contributions}

246 Y.B and A.M prepared the paper and the revision. R.P. performed the tracing and analyses. J.S. 247 parametrized the MRI sequences and optimized the MRI acquisition setup. L.V. and L.R. designed 248 and performed respectively the specific procedures of welfare, anesthesia, monitoring and preparation of baboons in the MRI machine. A.M. designed and supervised the study and MRI acquisitions.

\section{Ethics approval}

252 All animal procedures were approved by the "C2EA -71 Ethical Committee of neurosciences" (INT Marseille) under the number APAFIS\#13553-201802151547729 v4 and has been conducted at the

254 Station de Primatologie under the number agreement C130877 for conducting experiments on vertebrate animals (Rousset-Sur-Arc, France). All methods were performed in accordance with the relevant French law, CNRS guidelines and the European Union regulations (Directive 2010/63/EU). 


\section{References}

264

265

266

267

268

269

270

271

272

273

274

275

276

277

278

279

280

281

282

283

284

285

286

287

288

289

290

291

292

293

294

295

296

Becker Y, Sein J, Velly L, et al (2021) Early Left-Planum Temporale Asymmetry in Newborn Monkeys (Papio anubis): A longitudinal structural MRI study at two stages of development. NeuroImage 117575. https://doi.org/10.1016/j.neuroimage.2020.117575

Borovsky A, Saygin AP, Bates E, Dronkers N (2007) Lesion correlates of conversational speech production deficits. Neuropsychologia 45:2525-2533. https://doi.org/10.1016/j.neuropsychologia.2007.03.023

Chi JG, Dooling EC, Gilles FH (1977) Left-Right Asymmetries of the Temporal Speech Areas of the Human Fetus. Archives of Neurology 34:346-348. https://doi.org/10.1001/archneur.1977.00500180040008

Dehaene-Lambertz G, Dehaene S, Hertz-Pannier L (2002) Functional Neuroimaging of Speech Perception in Infants. Science 298:2013-2015. https://doi.org/10.1126/science.1077066

Dronkers NF, Wilkins DP, Van Valin RD, et al (2004) Lesion analysis of the brain areas involved in language comprehension. Cognition 92:145-177. https://doi.org/10.1016/j.cognition.2003.11.002

Dubois J, Benders M, Lazeyras F, et al (2010) Structural asymmetries of perisylvian regions in the preterm newborn. NeuroImage 52:32-42. https://doi.org/10.1016/j.neuroimage.2010.03.054

Foundas AL, Bollich AM, Feldman J, et al (2004) Aberrant auditory processing and atypical planum temporale in developmental stuttering. Neurology 63:1640-1646. https://doi.org/10.1212/01.WNL.0000142993.33158.2A

Gannon PJ, Holloway RL, Broadfield DC, Braun AR (1998) Asymmetry of Chimpanzee Planum Temporale: Humanlike Pattern of Wernicke's Brain Language Area Homolog. Science 279:220222. https://doi.org/10.1126/science.279.5348.220

Geschwind N, Levitsky W (1968) Human Brain: Left-Right Asymmetries in Temporal Speech Region. Science 161:186-187. https://doi.org/10.1126/science.161.3837.186

Glasel H, Leroy F, Dubois J, et al (2011) A robust cerebral asymmetry in the infant brain: The rightward superior temporal sulcus. NeuroImage 58:716-723. https://doi.org/10.1016/j.neuroimage.2011.06.016

Greve DN, Van der Haegen L, Cai Q, et al (2013) A surface-based analysis of language lateralization and cortical asymmetry. J Cogn Neurosci 25:1477-1492. https://doi.org/10.1162/jocn_a_00405

Hill J, Inder T, Neil J, et al (2010) Similar patterns of cortical expansion during human development and evolution. Proceedings of the National Academy of Sciences 107:13135-13140. https://doi.org/10.1073/pnas.1001229107

Hopkins WD, Marino L, Rilling JK, MacGregor LA (1998) Planum temporale asymmetries in great apes as revealed by magnetic resonance imaging (MRI). NeuroReport 9:2913-2918 
301

302

303

Hopkins WD, Nir TM (2010) Planum temporale surface area and grey matter asymmetries in chimpanzees (Pan troglodytes): The effect of handedness and comparison with findings in humans. Behavioural Brain Research 208:436-443. https://doi.org/10.1016/j.bbr.2009.12.012

Hopkins, W. D., Taglialatela, J. P., Meguerditchian, A., Nir, T., Schenker, N. M., \& Sherwood, C. C. (2008). Gray matter asymmetries in chimpanzees as revealed by voxel-based morphology. Neuroimage, 42, 491-497.

Josse G, Hervé P-Y, Crivello F, et al (2006) Hemispheric specialization for language: Brain volume matters. Brain Research 1068:184-193. https://doi.org/10.1016/j.brainres.2005.11.037

Keller SS, Roberts N, García-Fiñana M, et al (2010) Can the Language-dominant Hemisphere Be Predicted by Brain Anatomy? Journal of Cognitive Neuroscience 23:2013-2029. https://doi.org/10.1162/jocn.2010.21563

Liebal, K., Waller, B. M., Burrows, A. M., \& Slocombe, K. E. (2013). Primate communication: A multimodal approach. Cambridge: Cambridge University Press.

Lyn, H., Pierre, P., Bennett, A. J., Fears, S., Woods, R., \& Hopkins, W. D. (2011). Planum temporale grey matter asymmetries in chimpanzees (Pan troglodytes), vervet (Chlorocebus aethiops sabaeus), rhesus (Macaca mulatta) and bonnet (Macaca radiata) monkeys. Neuropsychologia, 49, 2004-2012.

Manjón JV, Coupé P, Martí $\square$ Bonmatí L, et al (2010) Adaptive non-local means denoising of MR images with spatially varying noise levels. Journal of Magnetic Resonance Imaging 31:192-203. https://doi.org/10.1002/jmri.22003

Marie D, Roth M, Lacoste R, et al (2018) Left Brain Asymmetry of the Planum Temporale in a Nonhominid Primate: Redefining the Origin of Brain Specialization for Language. Cereb Cortex 28:1808-1815. https://doi.org/10.1093/cercor/bhx096

Meguerditchian A, Gardner MJ, Schapiro SJ, Hopkins WD (2012) The sound of one-hand clapping: handedness and perisylvian neural correlates of a communicative gesture in chimpanzees. Proc Biol Sci 279:1959-1966. https://doi.org/10.1098/rspb.2011.2485

Meguerditchian A, Vauclair J, Hopkins WD (2013) On the origins of human handedness and language: A comparative review of hand preferences for bimanual coordinated actions and gestural communication in nonhuman primates. Developmental Psychobiology 55:637-650. https://doi.org/10.1002/dev.21150

Molesti, S., Meguerditchian, A., \& Bourjade, M. (2020). Gestural communication in olive baboons (Papio anubis): repertoire and intentionality. Animal Cognition, 23, 19-40.

Ocklenburg S, Friedrich P, Fraenz C, et al (2018) Neurite architecture of the planum temporale predicts neurophysiological processing of auditory speech. Science Advances 4:eaar6830. https://doi.org/10.1126/sciadv.aar6830 
332 Shapleske J, Rossell SL, Woodruff PWR, David AS (1999) The planum temporale: a systematic,

333 quantitative review of its structural, functional and clinical significance. Brain Research Reviews

334 29:26-49. https://doi.org/10.1016/S0165-0173(98)00047-2

335 Spocter MA, Sherwood CC, Schapiro SJ, Hopkins WD (2020) Reproducibility of leftward planum

336 temporale asymmetries in two genetically isolated populations of chimpanzees (Pan troglodytes).

337 Proc R Soc B 287:20201320. https://doi.org/10.1098/rspb.2020.1320

338 Tzourio-Mazoyer N, Crivello F, Mazoyer B (2018) Is the planum temporale surface area a marker of

339 hemispheric or regional language lateralization? Brain Struct Funct 223:1217-1228.

$340 \quad$ https://doi.org/10.1007/s00429-017-1551-7

341 Vigneau M, Beaucousin V, Hervé PY, et al (2006) Meta-analyzing left hemisphere language areas:

342 Phonology, semantics, and sentence processing. NeuroImage 30:1414-1432.

343 https://doi.org/10.1016/j.neuroimage.2005.11.002

344 Wada JA (1975) Cerebral Hemispheric Asymmetry in Humans: Cortical Speech Zones in 100 Adult

345 and 100 Infant Brains. Archives of Neurology 32:239.

$346 \quad$ https://doi.org/10.1001/archneur.1975.00490460055007

347 Wernicke C (1874) Der aphasische Symptomencomplex: Eine psychologische Studie auf

348 anatomischer Basis. Cohn.

349 Witelson SF, Pallie W (1973) Left Hemisphere Specialization for Language in the Newborn:

350 neuroanatomical Evidence of Asymmetry. Brain 96:641-646.

$351 \quad$ https://doi.org/10.1093/brain/96.3.641

352 Xia, J., Wang, F., Wu, Z., Wang, L., Zhang, C., Shen, D., Li, G., 2019. Mapping hemispheric

353 asymmetries of the macaque cerebral cortex during early brain development. Hum. Brain Map.

354 doi: $10.1002 / \mathrm{hbm} .24789$. 